\title{
The Pitfalls Of Multiple Dummy Variables In A Regression
}

Yi Ren, Ph.D., University of Scranton, USA

Dong Xiao, Ph.D., Northeastern University, USA

\begin{abstract}
This study reports long-been-neglected pitfalls when using multiple dummy variables in a regression model. We conduct simulation analysis to explain the mathematical meaning of a product term of two dummy variables, and find that the interaction dummy term indicates only the extra contribution, not the additive contribution of two dummies. The results suggest that testing and estimating interaction effects of dummy variables are not meaningful, and that dummy variable techniques should be handled carefully when introducing two or more dummies in a multiple regression model.
\end{abstract}

Keywords: Multiple Dummy Variables in a Regression; Multiple Regression Analysis

\section{INTRODUCTION}

C

$\mathrm{t}$ is common to see that dummy variables are used for modeling of empirical research in the social sciences, such as accounting or finance (e.g., Cheng, 2004; Degeorge, Jenter, Moel, and Tufano, 2004; Desai, Foley, and Hines,Jr., 2004; Ettredge, Kwon, Smith, and Zarowin, 2005; Evans, Kim, and Nagarajan, 2006; Kalyta, 2009; Katz, 2009; Morsfield and Tan, 2006; Omer, Bedard, and Falsetta, 2006; Perry and Zenner, 2001). The dummy variables can be easily used to study whether there are statistical differences among several sample groups. They are particularly useful when qualitative variables such as gender, education and ethnic groups etc. need to be included in the analysis (Gujarati 1970a, 1970b). However, it appears to us that if two or more dummy variables are included in a regression model, there are pitfalls that previous literature has not paid much attention to.

We conduct a simulation analysis to analyze the mathematical meanings of each term in a multiple regression with two dummy variables. We find the attributes of interaction dummy terms on hypothesis testing, for which we argue the interaction terms cannot be used to examine the differences between the test group and other groups, but indicate extra contributions that cannot be found when each dummy is considered individually.

For an example, two workers, working alone, will produce 8 and 10 products per hour, respectively. Working together, they will produce 20 products per hour. Much like the extra 2 products produced by two workers working together compared to the sum of products produced by working alone, the interaction dummy term indicates only the extra contribution, not the additive contribution of two dummies. Our results suggest that estimating and testing the interaction term of two dummy variables does not serve comparison purposes between the test group and any other groups or any other groups combined. In addition, testing statistical significance in regression including two dummy variables is not as accurate as that in regression including only one dummy, especially when sizes of compared groups are significantly different. The remainder of this study is organized as follows: Section 2 presents simulation analysis and results. Section 3 provides a conclusion.

\section{RESEARCH DESIGN AND RESULTS}

We construct a sample of 100 observations from a hypothetical company. These data are classified into two departments -30 observations are from its accounting department and 70 are from its sales department. Among the observations from the accounting department, 15 observations are from male employees and the other 15 
observations are from female employees. Among the observations from the sales department, 40 are from male employees and the other 30 are from female employees. Suppose we want to find out if the relationship between salary and effective tax rate differs due to gender effect and/or department effect. We first generate the employee's salary information (in million dollars). Then, we assign the effective tax rates to each employee. In practice, the tax rate is the ratio of income tax to taxable income. And a taxable income is the difference between a gross income and all allowable deductions. Generally, information on individual tax deductions is not available. Therefore, to make the data resemble a real world case, we calculated employees' effective tax rates based on their gross income and income tax using the formula: tax_rate $=$ income tax/gross income. The data is attached in the appendix. The following regression model is established with two dummy variables $D_{s}$ and $D_{d}$ :

tax_rate $=\beta_{0}+\beta_{1} \times D_{s}+\beta_{2} \times D_{d}+\beta_{3} \times D_{s} \times D_{d}+\beta_{4} \times$ Salary $+\beta_{5} \times D_{s} \times$ Salary $+\beta_{6} \times D_{d} \times$ Salary

$+\overline{\beta_{7}} \times D_{s} \times D_{d} \times$ Salary $+\varepsilon$,

Where

$$
D_{s}= \begin{cases}1 & \text { if the employee's gender is female } \\ 0 & \text { If the employee's gender is male }\end{cases}
$$

and

$$
D_{d}= \begin{cases}1 & \text { if the employee is in the sales department } \\ 0 & \text { if the employee is in the accounting department }\end{cases}
$$

\begin{tabular}{|c|c|}
\hline $\begin{array}{l}\text { Male, Accounting } \\
\qquad D_{\mathrm{s}}=0, D_{\mathrm{d}}=0\end{array}$ & $\begin{array}{l}\text { Male, Sales } \\
D_{s}=0, D_{d}=1\end{array}$ \\
\hline $\begin{array}{cc} & \text { Female, Accounting } \\
& \mathrm{D}_{\mathrm{s}}=1, \mathrm{D}_{\mathrm{d}}=0\end{array}$ & $\begin{array}{c}\text { Female, Sales } \\
D_{s}=1, D_{d}=1\end{array}$ \\
\hline
\end{tabular}

Based on the model, we may categorize the database according to four groups as sketched in the following graph:

Four colors--grey, red, blue and green--are marked to symbolize the four groups for the convenience of later references. The regression results are summarized in Table 1.

It seems very convenient to run one regression by including two dummy variables in a model. However, by analyzing term by term of Eq. (1), we identify the pitfalls on which practice in business research have long been ignored. The Intercept and Salary terms $\beta_{0}$ and $\beta_{4} \times$ Salary correspond to the gray group (male, accounting) when both $D_{s}=0$ and $D_{d}=0$, normally referred to as the base terms. The term $\beta_{1} \times D_{s}$ mathematically represents the contribution of the dummy variable $D_{s}$ to the intercept irreverent to the value of dummy variable $D_{d}$ taken (e.g., $D_{d}=0$ or $D_{d}=1$ ). Here for $D_{d}=0$, the dummy $D_{s}$ 's contribution to the intercept is $\beta_{1} \times D_{s}$ and for $D_{d}=1$ the dummy $D_{s}$ 's contribution to the intercept is $\left(\beta_{1}+\beta_{3}\right) \times D_{s}$. Thus, the common contribution to the intercept is $\beta_{1} \times D_{s}$. Similarly, the term $\beta_{5} \times D_{s} \times$ Salary represents the common interactions of dummy variable $D_{s}$ and variable Salary in either $D_{d}=0$ or $D_{d}=1$ cases. The terms $\beta_{1} \times D_{s}$ and $\beta_{5} \times D_{s} \times$ Salary represent the common contribution of dummy $D_{s}$ in Eq. (1). By setting $D_{\mathrm{d}}=0$ in Eq. (1), we will have 
tax_rate $=\beta_{0}+\beta_{1} \times D_{s}+\beta_{4} \times$ Salary $+\beta_{5} \times D_{s} \times$ Salary $+\varepsilon$.

where $D_{s}$ takes a value of 1 for female employees and 0 otherwise. All terms in Eq. (2) have the same mathematical meanings as in Eq. (1). The coefficients of terms in Eq. (2) are supposed to tell us the differences between the blue group (Female, Accounting) and the grey group (Male, Accounting). Before we proceed further, let us first present the regression results of Eq. (2) applied to the Accounting Department and Sales Department, respectively. Table 2 reports the results.

Table 1

Tax-Salary Regression

Including two dummies in the Model

\begin{tabular}{lccc}
\multicolumn{4}{c}{ tax_rate $=\beta_{0}+\beta_{1} \times D_{s}+\beta_{2} \times D_{d}+\beta_{3} \times D_{s} \times D_{d}+\beta_{4} \times$ Salary $+\beta_{5} \times D_{s} \times$ Salary } \\
$+\beta_{6} \times D_{d} \times$ Salary $+\beta_{7} \times D_{s} \times D_{d} \times$ Salary $+\varepsilon$ & - \\
\hline Terms & Coeff. & t-value & P $>|\mathbf{t}|$ \\
\hline Intercept & -0.054 & -1.07 & 0.286 \\
Salary & 2.882 & $3.54 * * *$ & 0.001 \\
$D_{s}$ & 0.144 & $1.99 * *$ & 0.049 \\
$D_{d}$ & -0.126 & $-1.94 *$ & 0.055 \\
$D_{s} \times D_{d}$ & -0.032 & -0.33 & 0.745 \\
$D_{s} \times$ Salary & -2.304 & $-1.83^{*}$ & 0.07 \\
$D_{d} \times$ Salary & 1.577 & 1.61 & 0.111 \\
$D_{s} \times D_{d} \times$ Salary & 0.871 & 0.56 & 0.578 \\
$N$ & & 100 & \\
Adjusted $R^{2}$ & & 0.5 & \\
$F$-value & & 14.55 & \\
\hline
\end{tabular}

$*, * *, * * *$ Indicate significance at the 10,5 , and 1 percent levels, respectively.

As Table 1 and Table 2 show, the coefficients of the two terms $\beta_{1} \times D_{s}$ and $\beta_{5} \times D_{s} \times$ Salary in both models are the same (0.144 and -2.304). This strongly indicates that the mathematical meanings of these two terms remain the same in the two models. However, the $t$ values of the coefficients of terms $\beta_{1} \times D_{s}$ and $\beta_{5} \times D_{s} \times$ Salary $(t=1.99$, $\mathrm{p}=0.049 ; \mathrm{t}=-1.83, \mathrm{p}=0.07$ ) indicate a statistical significance in Eq. (1) (with two dummy variables), while $\mathrm{t}$ values of the coefficients of these two terms in Eq. (2) does not indicate any statistical significance $(t=1.57, p=0.13 ; t=-0.64$, $\mathrm{p}=0.16$ ). As we know, the obvious discrepancies in testing statistical significances are due to the difference in sample sizes of the two models. The issue becomes more severe when the sample size of the two models differs a lot. The same problem also happens when we use the regression model with one dummy variable. For example, we should not use Eq. (2) to test the significance of the coefficients of the base terms $\beta_{0}$ and $\beta_{1} \times$ Salary. To correctly test the significance of the grey group (Male, Accounting), we need a regression model that only includes the grey group.

Table 2

Tax-Salary Regressions

Including only gender dummy

\begin{tabular}{|c|c|c|c|c|c|c|}
\hline & \multicolumn{3}{|c|}{ Accounting Dept. } & \multicolumn{3}{|c|}{ Sales Dept. $^{+}$} \\
\hline & Coeff. & t-value & $P>|t|$ & Coeff. & t-value & $P>|t|$ \\
\hline Intercept & -0.054 & -0.85 & 0.404 & -0.180 & $-4.99 * * *$ & 0.000 \\
\hline Salary & 2.882 & $2.8 * * *$ & 0.009 & 4.459 & $9.34 * * *$ & 0.000 \\
\hline$D_{s}$ & 0.144 & 1.57 & 0.128 & 0.112 & $1.99 * *$ & 0.05 \\
\hline$D_{s} x$ Salary & -2.304 & -1.45 & 0.159 & -1.434 & $-1.77 *$ & 0.081 \\
\hline & & 30 & & & 70 & \\
\hline Adjusted $R^{2}$ & & 0.15 & & & 0.61 & \\
\hline F-value & & 2.7 & & & 37.3 & \\
\hline
\end{tabular}

+ The results in Sales Department will be used in later comparisons and they are presented here to save the space.

$*, * *, * * *$ Indicate significance at the 10,5 , and 1 percent levels, respectively. 
Thus, we extend our analysis to the terms of $\beta_{2} \times D_{d}$ and $\beta_{6} \times D_{d} \times$ Salary. Mathematically, they represent the common contributions of the dummy variable $\mathrm{D}_{\mathrm{d}}$ to the intercept and the slope of salary, respectively. When $\mathrm{D}_{\mathrm{s}}=0$, Eq. (1) becomes

tax_rate $=\beta_{0}+\beta_{2} \times D_{d}+\beta_{4} \times$ Salary $+\beta_{6} \times D_{d} \times$ Salary $+\varepsilon$.

The coefficients of terms $\beta_{2} \times D_{d}$ and $\beta_{6} \times D_{d} \times$ Salary are supposed to tell us whether the tax-salary regressions for the red group (Male, Sales) and the grey group (Male, Accounting) are different.

Table 3 reports the results of Eq. (3) applied to Male group and Female group, respectively. As results of Table 1 and Table 3 show, the coefficients of $\beta_{2}$ and $\beta_{6}$ are the same in both Eq. (1) and Eq. (3) (-0.126 and 1.577) that indicate the same mathematical meanings of these terms in both models, while the differences in the coefficient significance still exist between Eq. (1) and Eq. (3) similar to the previous case. The t value of $\beta_{2}$ in Eq. (1) is -1.94 $(\mathrm{p}=0.06)$, and the $t$ value of $\beta_{2}$ in Eq. (3) is $-2.02(\mathrm{p}=0.05)$; the $t$ value of $\beta_{6}$ in Eq. (1) is $1.61(\mathrm{p}=0.11)$, and the $t$ value of $\beta_{6}$ in Eq. (3) is $1.67(\mathrm{p}=0.10)$.

Referring to Eq. (2) and Eq. (3) which are derived from Eq. (1) when we set $\mathrm{D}_{\mathrm{d}}=0$ and $\mathrm{D}_{\mathrm{s}}=0$, respectively, we see that there are differences between using one dummy variable and using two dummy variables in a regression model. Specifically, the results of testing statistical significances are changed. Now we move to analyze the interaction terms of the dummy variables, $\beta_{3} \times D_{s} \times D_{d}$ and $\beta_{7} \times D_{s} \times D_{d} \times$ Salary. They normally represent the most important statistical inferences in the model since these interaction terms are the reasons for adopting a model with interaction dummy variables. In our simulation example, they stand for the green group (Female, Sales) since the interaction only exists when both dummy variables take the value of 1 . Well accepted in previous literature, these terms may tell us the difference between the test group (when both dummy variables take value of 1) and the other groups. Here the test group is the green group. From the results of Table 1, the coefficients of the interaction terms $\beta_{3}$ and $\beta_{7}$ in Eq. (1) are -0.032 and 0.871 , and are both insignificant with t values of $-0.33(\mathrm{p}=0.75)$ and 0.56 $(\mathrm{p}=0.58)$, respectively. However, the results of sales department in Table 2 indicate that there are significant differences on both intercept $\left(\beta_{1}=0.112, \mathrm{p}=0.05\right)$ and slope $\left(\beta_{5}=-1.434, \mathrm{p}=0.08\right)$ between the red group (Male, Sales) and the green group (Female, Sales). Similarly, the results of "Female" in Table 3 indicate that there are significant differences on the intercept $\left(\beta_{2}=-0.157, \mathrm{p}=0.04\right)$ and slope $\left(\beta_{6}=2.447, \mathrm{p}=0.06\right)$ between blue group (Female, Accounting) and Green group (Female, Sales). Now the question arises from the comparison of utilizing one dummy vs. two dummies in a regression model: What does the role of interaction dummies reveal? Specifically, what do $\mathrm{D}_{\mathrm{s}} \times \mathrm{D}_{\mathrm{d}}$ and $\mathrm{D}_{\mathrm{s}} \times \mathrm{D}_{\mathrm{d}} \times$ Salary terms tell us?

Table 3

Tax-Salary Regressions Including only department dummy

\begin{tabular}{|c|c|c|c|c|c|c|}
\hline & \multicolumn{3}{|c|}{ Male } & \multicolumn{3}{|c|}{ Female $^{+}$} \\
\hline & Coeff. & t-value & $P>|t|$ & Coeff. & $t$-value & $P>\mid \mathbf{t}$ \\
\hline Intercept & -0.054 & -1.11 & 0.27 & 0.090 & 1.66 & 0.105 \\
\hline Salary & 2.882 & $3.68^{* * *}$ & 0.001 & 0.578 & 0.58 & 0.567 \\
\hline$D_{d}$ & -0.126 & $-2.02 * *$ & 0.049 & -0.157 & $-2.1 * *$ & 0.042 \\
\hline$D_{d} x$ Salary & 1.577 & 1.67 & 0.101 & 2.447 & $1.93 *$ & 0.061 \\
\hline & & 55 & & & 45 & \\
\hline Adjusted $R^{2}$ & & 0.62 & & & 0.22 & \\
\hline F-value & & 30 & & & 5.2 & \\
\hline
\end{tabular}

So far, we have discussed terms with one dummy variable in the tax-salary regression model. To address the effect of gender, the terms $\beta_{1} \times D_{s}$ and $\beta_{5} \times D_{s} \times$ Salary represent the contributions of the dummy variable $D_{s}$. Similarly, the terms $\beta_{2} \times D_{d}$ and $\beta_{6} \times D_{d} \times$ Salary represent the contributions of the dummy variable $D_{d}$, which is used to address the effect of the Department. Mathematically, the terms $\beta_{3} \times D_{s} \times D_{d}$ and $\beta_{7} \times D_{s} \times D_{d} \times$ Salary represent the 
extra contributions when both dummy variables take the value of 1 . Where is the extra contribution from? It comes from the interactions of the two dummy variables, i.e., the correlation. In Eq. (1), the two dummies in the multiplicative form represent the contribution that cannot be explained by adding the contributions of each dummy variable working alone. A simple example may help to explain the interaction terms' mathematical meaning as we illustrated in the Introduction section. Worker A who may produce 10 products per hour in a workshop working alone and worker B who alone may produce 8 products per hour. If the two workers work together in the workshop, they will produce 20 products per hour instead of 18 products per hour. So there are 2 extra products produced each hour when the two workers work together. The interaction terms are not to show the difference between worker A working alone $(10 / \mathrm{hr})$, worker B working alone $(8 / \mathrm{hr})$ or even no worker $(0 / \mathrm{hr})$, and two workers working together (20/hr). They are supposed to show the extra contributions $(2 / \mathrm{hr})$. Thus, these terms cannot be used to tell us whether the green group (Female, Sales) is different from any other groups. It only tells us whether the interaction of the dummies has contributed significant influence on the model or not. Unfortunately, there is no equivalent model without changing the meaning of these two terms. For example, we may choose the following model:

$$
\text { tax_rate }=\alpha_{0}+\alpha_{1} \times D_{s} \times D_{d}+\alpha_{2} \times \text { Salary }+\alpha_{3} \times D_{s} \times D_{d} \times \text { Salary }+\varepsilon
$$

Table 4

Tax-Salary Regressions

Include only interaction of two dummies

\begin{tabular}{lcccccc}
\multicolumn{4}{c}{ tax_rate $=\alpha_{0}+\alpha_{1} \times D_{s} \times D_{d}+\alpha_{2} \times$ Salary $+\alpha_{3} \times D_{s} \times D_{d} \times$ Salary $+\varepsilon$} \\
\hline \multicolumn{3}{c}{ Grey vs. Green } & \multicolumn{3}{c}{ Grey, Red and Blue vs. Green } \\
\hline Intercept & Coeff. & t-value & $\mathbf{P}>|\mathbf{t}|$ & Coeff. & t-value & P $>|\mathbf{t}|$ \\
Salary & -0.054 & -0.9 & 0.375 & -0.055 & $-2.12^{* *}$ & 0.036 \\
$D_{s} \times D_{d}$ & 2.882 & $2.96^{* * *}$ & 0.005 & 2.896 & $7.63^{* * *}$ & 0.000 \\
$D_{s} \times D_{d} \times$ Salary & -0.014 & -0.16 & 0.871 & -0.012 & -0.21 & 0.834 \\
$N$ & 0.143 & 0.11 & 0.914 & 0.129 & 0.15 & 0.884 \\
Adjusted $R^{2}$ & & 45 & & & 0.41 & 24.3 \\
$F$-value & & 0.29 & & & 24 \\
\hline
\end{tabular}

$*, * *, * * *$ Indicate significance at the 10,5 , and 1 percent levels, respectively.

We may use Eq. (4) to compare the difference between the grey group (Male, Accounting) and the green group (Female, Sales). In this case, the contributions of dummy variables working alone are put into the interaction terms and thus the meaning of these interaction terms is changed. Also, by still using Eq. (4), we may compare the difference between the other three groups and the green group. However, Eq. (4) changes not only the interaction terms' meanings but also those of the base terms. Let us look at the results of Eq. (4) shown in Table 4. The right columns of Table 4 report the comparison between the Grey group (Male, Accounting) and the Green group (Female, Sales), the coefficients of the base terms are the same in both Eq. (1) and Eq. (4) $\left(\alpha_{0}=\beta_{0}=-0.054\right.$ and $\alpha_{2}=\beta_{4}=2.882$ ). However, the coefficients of the interaction terms in Eq. (4) are different from the interactions terms in Eq. (1), which suggest the interaction terms in Eq. (4) and Eq. (1) represent different contributions. The coefficients $\alpha_{1}$ and $\alpha_{2}$ of Eq. (4) actually are the sums of the corresponding terms' coefficients in Eq. (1), i.e.

$\alpha_{0}=\beta_{0}, \alpha_{1}=\beta_{1}+\beta_{2}+\beta_{3}, \alpha_{2}=\beta_{4}$, and $\alpha_{3}=\beta_{5}+\beta_{6}+\beta_{7}$.

The left columns of Table (4) report the results of the Grey, Red and Blue groups (observations other than the Green group) Vs. Green group (Female, Sales) which indicate larger deviations from the results of Eq. (1) -- not only have the interaction terms changed, but also the base terms have changed. We observe that the coefficients of all terms in Table 4 are different from the coefficients of the corresponding terms in Table 1.

From the tax-salary regression example, we find two main pitfalls when we use two or more dummy variable in a regression model. The first pitfall exists in the interaction terms of the model. The mathematical meaning of the interaction terms is the contributions of the two dummy variables' interaction. It shows the extra contribution that cannot be reflected by using dummy variables individually. And the interaction terms lack the definite physical meaning as we show in the example. They do not represent the differences between the Green 
group (Female, Sales) and any other group or any other combination of the groups. The lack of physical meaning makes it hard to interpret the results. When we use two dummy variables in the model, we are normally more interested in comparing the group of both $D_{s}=1$ and $D_{d}=1$ to the other groups such as $D_{s}=0$ and $D_{d}=1$, and/or $D_{s}=1$ and $D_{d}=0$. For example, as we have indicated in the previous discussion, our results show that there are significant differences between the red group and green group (refer to "Sales Dept" in Table 2), and significant differences between the blue group and the green group (refer to "Female" in Table 3), but there are insignificant coefficients of the green group shown in Table 1. The obvious discrepancies justify our interpretation of the multiplicative terms of two dummy variables.

Table 5

Tax-Salary Regressions

Comparison between model including two dummies and one dummy

\begin{tabular}{lcccccc}
\hline & \multicolumn{2}{c}{ Model with two dummy variables } & \multicolumn{3}{c}{ Models with one dummy variable } \\
\hline & Coeff. & t-value & $\mathbf{P}>|\mathbf{t}|$ & Coeff. & t-value & $\mathbf{P}>|\mathbf{t}|$ \\
$D_{s}$ & 0.144 & $1.99^{* *}$ & 0.049 & 0.144 & 1.57 & 0.128 \\
$D_{d}$ & -0.126 & $-1.94^{*}$ & 0.055 & -2.304 & -0.64 & 0.159 \\
$D_{s} x$ Salary & -2.304 & $-1.83^{*}$ & 0.07 & -0.126 & $-2.02^{* *}$ & 0.049 \\
$D_{d} x$ Salary & 1.577 & 1.61 & 0.111 & 1.577 & 1.67 & 0.101 \\
\hline
\end{tabular}

$*, * *, * * *$ Indicate significance at the 10,5 , and 1 percent levels, respectively.

The second pitfall is well known even for a model with one dummy variable. Due to the inclusion of the other group, the sample size is changed. Thus, the statistical significance of the base terms in the model of one dummy variable is modified due to the change in sample size. In a model with two dummy variables such as Eq. (1), the same size-change effect causes the change in testing statistical significance of the single dummy terms as well as the base terms. Table 5 summarizes the differences in testing statistical significance between the model with two dummy variables (Eq. (1)) and the model with one dummy variable (Eq. (2) and Eq. (3)). While a model with two dummy variables is very convenient in a lot of situations, the results may deviate from what we expect. In our example, the coefficient of the gender dummy in the model with two dummy variables is the same as the model with one dummy variable. They are 0.144 in both models. But, the $\mathrm{p}$ values are different $(0.05$ vs. 0.13$)$. Moreover, the coefficients of the department dummy are different between models with two dummies and the model with one dummy (-0.126 vs. -2.304$)$, as well as differences in $\mathrm{p}$ value $(0.06$ vs. 0.16$)$. Therefore, it is unwise to include observations in the Sales department when we compare the gender difference in the Accounting department.

\section{CONCLUSIONS}

In this paper, we provide evidence of pitfalls when using multiple dummy variables in a regression model. We use a sample that simulates the real world case to investigate association between effective tax rate and salary among four groups, in the colors of grey, red, green, and blue. Two dummy variables, a gender dummy and a department dummy are applied in tax-salary regressions. We compare the results between the model that includes both dummies and models that include each dummy, respectively. In some research designs, the interaction terms of two dummy variables are used to indicate the differences between the test group when both dummy variables take value of 1 and other groups. Our results show discrepancies in using regressions with one dummy and regressions with two dummies. The mathematical meaning of interaction term of dummy variables is the extra contribution that cannot be reflected by using each dummy variable separately. Our analysis suggests that interaction dummy terms cannot be used to examine the differences between the test group and other groups.

In addition, the coefficients of each dummy in two-dummy regression model are the same as the corresponding coefficients in one-dummy regression models. Our result verifies that the meaning of single dummy terms does not change when including multiple dummies in a regression. However, testing statistical significance is changed due to the change in sample size. Our analysis indicates that testing statistical significance will significantly change when sizes of compared groups are significantly different. We recommend that application of multiple dummy variables in a regression model should be handled carefully. 


\section{AUTHORS INFORMATION}

Yi Ren, Ph.D., University of Scranton, Department of Accounting, Scranton, PA 18510. She earned a doctoral degree in accountancy from Southern Illinois University. E-mail: yi.ren@ scranton.edu (Corresponding author)

Dong Xiao, earned Ph.D. degree at North Carolina State University. Currently he is an Research Associate at Northeastern University.

\section{REFERENCES}

1. Cheng, S., 2004. R\&D expenditures and CEO compensation. The Accounting Review, 79 305-328.

2. Degeorge, F., Jenter, D., Moel, A., Tufano, P., 2004. Selling company shares to reluctant employees: France Telecom's experience. Journal of Financial Economics, 71 169-202

3. Desai, M.A., Foley, C.F., Hines, J.R. Jr., 2004. The cost of shared ownership: evidence from international joint ventures. Journal of Financial Economics, 73 323-374.

4. $\quad$ Ettredge, M.L., Kwon, S.Y., Smith, D.B., Zarowin, P.A., 2005. The impact of SFAS No.131 business segment data on the market's ability to anticipate future earnings. The Accounting Review, 80 773-804.

5. Evans, J.H,III, Kim, K., Nagarajan, N.J., 2006. Uncertainty, legal liability, and incentive contracts. The Accounting Review, 81 1045-1071.

6. Gujarati, D., 1970. Use of dummy variables in testing for equality between sets of coefficients in two liner regressions: a note. The American Statistician, 24(1) 50-52

7. Gujarati, D., 1970. Use of Dummy variables in testing for equality between sets of coefficients in linear regressions: a generalization. The American Statistician, 24(5) 18-22

8. Kalyta, P., 2009. Accounting discretion, horizon problem, and CEO retirement benefits. The Accounting Review, 84 1553-1573.

9. Katz, S.P., 2009. Earnings quality and ownership structure: the role of private equity sponsors. The Accounting Review, 84 623-658.

10. Morsfield, S.G., Tan., C.E.L., 2006. Do venture capitalists influence the decision to manage earnings in initial public offerings? The Accounting Review, 81 1119-1150.

11. Omer, T.C., Bedard, J.C., Falsetta, D., 2006. Auditor-provided tax services: the effects of a changing regulatory environment. The Accounting Review, 81 1095-1117.

12. Perry, T., Zenner, M., 2001. Pay for performance? Government regulation and the structure of compensation contracts. Journal of Financial Economics, 62 453-488. 


\section{APPENDIX 1}

The tax-salary sample data (Salary is in thousands)

\begin{tabular}{|c|c|c|c|c|c|c|c|}
\hline sex & dept & salary & tax_rate & sex & dept & salary & tax_rate \\
\hline $\mathrm{M}$ & acct & 0.03 & 0 & $\mathrm{M}$ & sale & 0.075 & 0.1 \\
\hline M & acct & 0.037 & 0.16 & M & sale & 0.075 & 0.16 \\
\hline $\mathrm{M}$ & acct & 0.044 & 0 & M & sale & 0.075 & 0.15 \\
\hline $\mathrm{M}$ & acct & 0.046 & 0.14 & M & sale & 0.076 & 0.15 \\
\hline $\mathrm{M}$ & acct & 0.051 & 0.03 & M & sale & 0.077 & 0.22 \\
\hline $\mathrm{M}$ & acct & 0.052 & 0.03 & M & sale & 0.077 & 0.14 \\
\hline $\mathrm{M}$ & acct & 0.053 & 0.15 & M & sale & 0.078 & 0.05 \\
\hline $\mathrm{M}$ & acct & 0.055 & 0.21 & M & sale & 0.079 & 0.16 \\
\hline $\mathrm{M}$ & acct & 0.06 & 0.19 & M & sale & 0.079 & 0.16 \\
\hline $\mathrm{M}$ & acct & 0.062 & 0.04 & M & sale & 0.08 & 0.2 \\
\hline $\mathrm{M}$ & acct & 0.065 & 0.01 & M & sale & 0.08 & 0.17 \\
\hline $\mathrm{M}$ & acct & 0.076 & 0.22 & M & sale & 0.085 & 0.26 \\
\hline $\mathrm{M}$ & acct & 0.077 & 0.11 & M & sale & 0.085 & 0.19 \\
\hline $\mathrm{M}$ & acct & 0.085 & 0.18 & M & sale & 0.087 & 0.27 \\
\hline $\mathrm{M}$ & acct & 0.094 & 0.28 & M & sale & 0.088 & 0.23 \\
\hline $\mathrm{F}$ & acct & 0.032 & 0.2 & M & sale & 0.092 & 0.26 \\
\hline $\mathrm{F}$ & acct & 0.034 & 0.06 & M & sale & 0.095 & 0.3 \\
\hline $\mathrm{F}$ & acct & 0.035 & 0.12 & M & sale & 0.1 & 0.29 \\
\hline $\mathrm{F}$ & acct & 0.038 & 0.15 & M & sale & 0.11 & 0.28 \\
\hline $\mathrm{F}$ & acct & 0.039 & 0 & M & sale & 0.12 & 0.31 \\
\hline $\mathrm{F}$ & acct & 0.044 & 0.16 & $\mathrm{~F}$ & sale & 0.043 & 0.05 \\
\hline $\mathrm{F}$ & acct & 0.046 & 0.13 & $\mathrm{~F}$ & sale & 0.045 & 0.07 \\
\hline $\mathrm{F}$ & acct & 0.052 & 0.06 & $\mathrm{~F}$ & sale & 0.048 & 0 \\
\hline $\mathrm{F}$ & acct & 0.056 & 0.12 & $\mathrm{~F}$ & sale & 0.05 & 0.07 \\
\hline $\mathrm{F}$ & acct & 0.059 & 0.13 & $\mathrm{~F}$ & sale & 0.05 & 0.1 \\
\hline $\mathrm{F}$ & acct & 0.062 & 0.09 & $\mathrm{~F}$ & sale & 0.052 & 0.06 \\
\hline $\mathrm{F}$ & acct & 0.065 & 0.12 & $\mathrm{~F}$ & sale & 0.055 & 0 \\
\hline $\mathrm{F}$ & acct & 0.07 & 0.22 & $\mathrm{~F}$ & sale & 0.055 & 0.2 \\
\hline $\mathrm{F}$ & acct & 0.073 & 0.11 & $\mathrm{~F}$ & sale & 0.056 & 0.08 \\
\hline $\mathrm{F}$ & acct & 0.077 & 0.13 & $\mathrm{~F}$ & sale & 0.057 & 0.05 \\
\hline $\mathrm{M}$ & sale & 0.043 & 0.04 & $\mathrm{~F}$ & sale & 0.06 & 0.15 \\
\hline $\mathrm{M}$ & sale & 0.047 & 0 & $\mathrm{~F}$ & sale & 0.06 & 0.12 \\
\hline $\mathrm{M}$ & sale & 0.052 & 0.02 & $\mathrm{~F}$ & sale & 0.06 & 0.17 \\
\hline $\mathrm{M}$ & sale & 0.055 & 0.08 & $\mathrm{~F}$ & sale & 0.06 & 0.2 \\
\hline $\mathrm{M}$ & sale & 0.057 & 0.06 & $\mathrm{~F}$ & sale & 0.062 & 0.08 \\
\hline $\mathrm{M}$ & sale & 0.058 & 0.1 & $\mathrm{~F}$ & sale & 0.065 & 0.09 \\
\hline $\mathrm{M}$ & sale & 0.06 & 0.14 & $\mathrm{~F}$ & sale & 0.067 & 0.15 \\
\hline $\mathrm{M}$ & sale & 0.06 & 0.1 & $\mathrm{~F}$ & sale & 0.068 & 0.1 \\
\hline $\mathrm{M}$ & sale & 0.061 & 0.08 & $\mathrm{~F}$ & sale & 0.068 & 0.28 \\
\hline $\mathrm{M}$ & sale & 0.062 & 0.12 & $\mathrm{~F}$ & sale & 0.069 & 0.11 \\
\hline $\mathrm{M}$ & sale & 0.062 & 0.05 & $\mathrm{~F}$ & sale & 0.07 & 0.16 \\
\hline $\mathrm{M}$ & sale & 0.064 & 0.15 & $\mathrm{~F}$ & sale & 0.07 & 0.11 \\
\hline $\mathrm{M}$ & sale & 0.066 & 0.1 & $\mathrm{~F}$ & sale & 0.072 & 0.28 \\
\hline $\mathrm{M}$ & sale & 0.067 & 0.07 & $\mathrm{~F}$ & sale & 0.073 & 0.13 \\
\hline $\mathrm{M}$ & sale & 0.067 & 0.17 & $\mathrm{~F}$ & sale & 0.075 & 0.16 \\
\hline $\mathrm{M}$ & sale & 0.069 & 0.1 & $\mathrm{~F}$ & sale & 0.078 & 0.17 \\
\hline $\mathrm{M}$ & sale & 0.07 & 0.14 & $\mathrm{~F}$ & sale & 0.082 & 0.18 \\
\hline $\mathrm{M}$ & sale & 0.071 & 0.09 & $\mathrm{~F}$ & sale & 0.085 & 0.16 \\
\hline M & sale & 0.071 & 0.13 & $\mathrm{~F}$ & sale & 0.093 & 0.2 \\
\hline $\mathrm{M}$ & sale & 0.073 & 0.17 & $\mathrm{~F}$ & sale & 0.098 & 0.18 \\
\hline
\end{tabular}

